\title{
CURRENT DEVELOPMENTS
}

\author{
GIVING EFFECT TO THE CONSTITUTION: HELPING \\ FAMILIES TO HELP THEMSELVES
}

\section{INTRODUCTION}

The South African Constitution demonstrates a desire to create a human rights culture in which everyone who needs it has access to the law. ${ }^{1}$ This sounds a very attainable aim, but is so only in a criminal law context and far less so where issues of family law are concerned. In a country with a relatively small legal profession and a great diversity in income and culture, family law tends to be the stepchild of the profession. It is not glamorous. It does not generate a large income for its practitioners, except those catering for the very small proportion of the population who are wealthy. The pool of clients is considerably smaller than the size of the population might suggest. Part of the population would not go to a lawyer at all for family law assistance, notably those regulating their relations purely by customary or religious law without any involvement of the civil law. Others prefer to resort to informal community courts, although these are often not suitable for such family matters as the enforcement of regular maintenance payments. But in the main, lack of income removes the option of employing the services of private practitioners for a large section of the population. An estimated 22 million people (over half of the population) live on an income of less that $\mathrm{R} 144,00$ per month, ${ }^{2}$ yet free or cheap family law advice is hard to come by. Those practitioners to whom poorer people do resort are themselves frequently from less affluent backgrounds and least able to afford to take on work for which they are not paid, especially as the granting of Legal Aid for divorces has long been subject to arbitrary decisions by Legal Aid officials. $^{3}$

Nonetheless, the importance of assistance in sorting out family legal problems cannot be overestimated. Their effects on the future of not only the generation involved, but the next one too, are frequently crucial and can threaten the very survival of the family in question. The complexities of custody and access arrangements, maintenance, the division of

1 Sections 34 and 91 of The Constitution of the Republic of South Africa Act 108 of 1996.

2 Briefing by Alliance for Children's Entitlement of Social Security (ACESS) to the Committee on the Child Support Grant and Social Security for Children; National Council of Provinces (18 June 2002).

3 Black Sash Annual Report 2001 (2002) 9; House of Assembly Debates col 1897-99 (31 January 198628 January 1987). 
property and what happens to the family home are some of the issues involved. Lack of suitable advice and assistance can be disastrous for the unprotected party and any dependants. Government therefore has an interest and a responsibility to ensure that legal advice on family matters is available.

In a country like South Africa with numerous urgent competing demands on the public purse, this is not easy to provide. The solutions adopted by first world countries are usually inappropriately expensive and based on different social mechanisms within their societies. Britain's latest initiative to provide legal advice on family problems, for example, the Legal Services Commission's Family Advice and Information Networks (FAINS), ${ }^{4}$ now in its pilot stage, is based on a recognition of

the fact that people with family law problems tend overwhelmingly to go to solicitors for advice. It thus uses solicitors as information providers and as gatekeeper/intermediaries for a range of advice and support service, including not only legal advice and representation but also, for example, marriage counselling and mediation services. ${ }^{5}$

This is a situation to which South Africa cannot aspire. It is true that in South Africa under apartheid various organisations came into being to provide free legal advice, inter alia on family matters such as maintenance. These included the Black Sash and various community organisations funded by opponents of apartheid, but all operated mainly on voluntary services provided by lay advisers. ${ }^{6}$ Since 1994 many have either gone out of existence or had to employ paid advisers, which requires constant fundraising and limits expansion.

The Department of Justice and Constitutional Development has itself considered various solutions. The training and recognition of paralegals is one, but this is currently, and has been for four years, enmeshed in debates on changes to the draft Legal Practices Bill. ${ }^{7}$ Legal Advice Centres at universities receive some state assistance, but generally lack the capacity to deal with the demand for legal assistance, especially in divorce matters, while Justice Centres mainly use the legal aid at their disposal for criminal cases. ${ }^{8}$ The pilot project divorce courts of the Family Courts, initiated in the 1990s, try to some extent to assist those seeking divorce without assistance from lawyers, but they lack both adequate time and

4 The Legal Services Commission's Family Advice and Information Networks is sponsored by the Lord Chancellor's Department.

5 Website of the Lord Chancellor's Department available through $<$ http://www.gov.uk/ $>$.

6 For a more extensive account and evaluation of their roles see $<$ http://www.paralegaladvi ce.org.za >; CASE Access to Justice in South Africa: Legal Aid Transformation and the Paralegal Movement (June 2000) available at <http://www.case.org.za $/ \mathrm{html} /$ legal3.hrm $>$.

7 The National Paralegal Institute of South Africa and the Legal Profession have submitted separate, conflicting draft bills to the Minister for his approval. Given the fundamental differences between the two, it is highly unlikely that a bill will be finalised in 2003 .

8 D Smart \& Y de Jong Radio Interview with J Orr SAFM (22 April 2002) (hereinafter 'radio interview'). 
facilities to make the courts less intimidating to those who seek assistance unaided by the legal profession. ${ }^{9}$ Again, lack of finances is at the root of the difficulty, but there is little hope of this being remedied. In June 2002 the Minister of Justice admitted that a recent costing exercise of unfunded activities in the Department had proved that an extra R2 billion was needed to deliver quality services. ${ }^{10}$

If the government, civil society, and the legal profession all have problems with providing affordable essential legal advice on family matters, the only other obvious solution is to look to some outside agency to provide at least a temporary remedy. However, such solutions tend to come at a price. The most obvious short-term risks are associated with lack of control of agency policy and practice. A major long-term risk is that when the agency eventually withdraws and is replaced by the relevant government department, it will be found that the agency has not passed on its hard-won experience of running the service and has not trained replacements from the government department. It is in the light of these difficulties that South Africa's latest solution needs to be examined and evaluated.

\section{A Public/Private Partnership}

One way to avoid the uncontrolled consultancy model of assistance has been the formation of partnerships with the private sector. Many government departments have adopted various partners in a variety of forms of partnership. The Minister of Social Development, for example, has spoken enthusiastically about his Department's partnerships with not only some 40 business leaders and the media, but also with faith-based organisations. These have been enlisted to deal with problems of capacity and accounting, with the Minister reserving particular praise for the Methodist and Catholic Churches' capacity to disburse poverty alleviation funds and monitor projects. ${ }^{11}$ The Department of Justice had itself been involved in various partnership models, some, such as the Asset Procurement and Operating Partnership System (APOPS), ${ }^{12}$ being more akin to outsourcing in that the motivation of the private entity was to operate for profit. A different model was provided by Business Against Crime (BAC), which was established in 1995 in response to a

9 S Burman; E Dingle \& N Glasser 'The South African Family Court: A First World Ideal in a Second World Country' in J Dewar \& S Parker (eds) Family Law: Processes, Practices, Pressure (2003) 117-34.

10 Minister of Justice and Constitutional Development Department Budget Vote (14 June 2002) available at $<$ http://www.gov.za/speeches/ index.html $>$.

11 GCIS Media Briefing (20 August 2002) available at <http://www.pmg.org.za/briefings/ aug2002/>.

12 In terms of this partnership, prisons were built in both Louis Trichardt and Bloemfontein and, after a specified time during which the companies are to run the prisons for their own profit, the prisons are to be handed over to the Department of Correctional Services. 
governmental appeal to the business sector to assist in combating crime. ${ }^{13}$ It was this concept which was adopted for the proposed partnership to bring family law assistance to all - that of bringing together public and private role-players with the sole intention of the private role-players rendering an improved service of what is essentially core public business. Similar models had been adopted in Singapore and Australia. ${ }^{14}$ In South Africa a partnership was formed to create a series of People's Family Law Centres. The first was launched on 22 March 2002 in Cape Town as a not-for-profit company, entering into a non-funding public/private partnership with the Department of Justice and Constitutional Development.

It was agreed that the Centre for Socio-Legal Research at the University of Cape Town should monitor and evaluate the new service, to ascertain how effectively it was fulfilling its remit. The research adopted a wholly qualitative approach. The initial study, of which this is a report, was conducted with both Centre staff and Family Law users. Individual in-depth interviews were held with the Executive Directors, the Centre's Joint Managing Directors, support staff, the principal mediator and with all the paralegals servicing the Centre. In addition, ten face-toface in-depth interviews were conducted with Centre users from a variety of ethnic backgrounds.

\section{The Aims and Vision of the Centre}

The primary aim of the Centre is 'to increase access to justice by providing an effective, affordable, accessible and professional services (sic) to clients in a self-sustainable manner'. ${ }^{15}$ The Centre's model of service provision is premised on the belief that self-representation, preceded by a system of user education combined with the provision of start-up documentation, is a viable alternative in family law matters. Instead of managing clients' cases, the aim is towards user empowerment. The client is informed of the full scope of the rights and obligations attaching to a particular problem and is thereby enabled to take control of his or her problem and to see the matter through to completion him- or herself. It is a system of assisted self-help. Should a matter become defended and require proper legal representation, the Centre has a panel of attorneys to whom they can refer their clients. In compiling the list of the panel, the Centre asked firms specialising in family law whether or not they wished to be part of the panel, and if so, to indicate their hourly rates. This is shown to the client, who is thus in a position to choose a firm appropriate to his or her financial standing and to know in advance

13 Interview with People's Family Law Centre Management (13 May 2002).

14 Radio interview (note 8 above).

15 E Baartman 'Building Blocks' conference paper delivered at the Miller du Toit conference on Family Law (26 March 2002) available at <http://www. pflc.org.za > . 
what the costs involved are. Offers by advocates and attorneys to act pro bono had not yet been taken up at the time of interview. ${ }^{16}$ In order to ensure that its systems and procedures operate correctly, the Centre has set itself the task of initially limiting its services to the following areas of family law: maintenance, maintenance enforcement, divorce, domestic violence, extra-marital access, pre-marital contracts and mediation.

It is the Centre's intention to extend the ambit of the services that it offers by adding additional areas of family-related law incrementally. Further, the Executive Directors are currently in the process of opening a Centre in Johannesburg and are planning one in Durban, and their medium to long-term aim is to cover rural areas as well. Ultimately it is intended that the running of the Centres will be transferred to the Department of Justice and Constitutional Development, ${ }^{17}$ possibly when the project expands its operations into the rural areas, where economic and demographic realities will make cross-subsidisation and sustainability extremely difficult. ${ }^{18}$

\section{The Centre's Relationship with the Department}

The purpose of the partnership between the Centre and the Department is twofold - improved service delivery and policy formation. The Department is committed to a non-exclusive endorsement of the services offered by the Centre. In order to facilitate this interaction, two teams have been established. The first is a National Steering Team, which resides within the Court Services Unit of the Department and is headed by the Deputy Director-General of the Department. This team is responsible for the overall smooth running of the project, and for ensuring regional co-operation and compliance with national policy. Although the Steering Team does not meet regularly, the Centre keeps it constantly informed and all policy issues are approved by this team. The second team operates on a regional level and is responsible for the actual implementation of service delivery. Thus for example, when the Centre designed its posters and advertising material, these were submitted to the Steering Committee for approval, whilst the approval to display these in court buildings was obtained from the Implementation Team. This is headed by the Regional Head of the Department of Justice and Constitutional Affairs, Western Cape, and meets on a monthly basis. Similar regional teams will be established as the project extends its operation to new regions. Should the Department not agree with a particular type or form of service, the Centre would be prohibited from using the Department's logo and from advertising that service within the

16 Interview (note 13 above).

17 Opening speech by the Deputy Minister of Justice and Constitutional Development at the launch of the People's Family Centre, Cape Town (22 March 2002).

18 Radio interview (note 8 above). 
court precincts. To this end, the Department enjoys the right of veto over the Centre's operations. However, should the Centre wish, for example, to extend its services to a new area, it could either elect to renegotiate terms with the Department, or simply introduce the service under its own logo.

Legal issues are generally intimidating for most people. Competing interests are at stake, the terminology is alien and the procedure to be followed is highly technical. Family law matters are even more daunting, not necessarily because of the inherent complexities, but rather because the person seeking recourse is often already emotionally traumatised as a result of the nature of the legal issues, which go to the core of that person's survival. Not only does this aggravate the emotional trauma of being unassisted; it may also result in the person applying for incorrect orders, bringing incorrect paperwork, and frustrating his or her matter. ${ }^{19}$ An added difficulty facing people with legal problems in the area of family law is the plethora of courts within any region, and specifically the lack of any uniform modus operandi or standard of service delivery within the various magisterial districts of a region. Apart from compounding the lot of the individual as he or she tries to navigate the procedural and legal labyrinths, a further consequence is that there is no standard basis for retrieving such data as is necessary to make informed improvements to the system. Thus, for example, despite a declared national policy to improve the lot of women and children, there are no available statistics on the number of maintenance cases or the average case-cycle time. Until such time as the Department of Justice is able accurately to track the processes and measure standards of service delivery, it will not be able to extract reliable data. In a first step to meet this need, the Centre and the Department have developed a filing system whereby the progress of cases can be accurately recorded. Based on an open book policy, all data is shared with the Department and vice versa, and the Department will, for the first time, be able to obtain the necessary data, courtesy of the Centre. ${ }^{20}$

\section{Modus Operandi of the Centre}

In attempting to provide services to more people, the Centre realised that innovative approaches would have to be adopted. It worked on the assumptions that the core business of the Department of Justice is the adjudication of cases, and that the quality of the papers before the Courts influences the effectiveness of adjudication. It therefore sought to create an improved pre-processing mechanism that would benefit both the majority of people and the Department. ${ }^{21}$

19 Ibid.

20 Interviews with Centre Management (13 May 2002; 30 May 2002; 14 August 2002).

21 Radio interview (note 8 above). 
A second innovative approach adopted by the Centre is its reliance on the use of specialised paralegals as the frontline service providers. Within the South African context, the term paralegal has historically tended to refer to people working alongside lawyers. Currently there is much debate around the restructuring of the legal profession with a view to increasing access to justice through the use of suitably trained and qualified paralegals. It is envisaged that areas of law previously reserved for lawyers will be opened to paralegals. Recognising that one way to address the problem of providing affordable and effective services was to optimise the ratio between the training costs and service delivery costs, the Centre embraced the concept of specialist paralegals. As their legal training is in a limited core area, the training time is relatively short and, as a result, their services can be provided at a lower rate than that of the formalised profession. Interestingly, all the paralegals employed by the Centre have tertiary education, and two are in fact attorneys. In advertising the posts, the Centre required that the applicants had experience in family law and a tertiary qualification, and it was anticipated that the majority of the applicants would be teachers or social workers. Contrary to expectations, the majority of applicants were in fact law graduates.

Irrespective of their previous training, at the commencement of work all the successful applicants underwent an intensive training programme developed in-house, which included briefing in both substantive family law and Centre procedures. Practical training was also provided through mock consultations. Further, the Centre provides continuous ongoing training two afternoons a week. One training session is used for peergroup learning, in which actual cases are discussed, whilst the second session is used for specific subject training by specialists in the field. In addition, the paralegals all receive continuous computer training. Staff development, which clearly comes at a price, is an integral part of the Centre's work ethic. Interesting questions perforce arise as to the financial viability of such staff development, as interviews with the paralegals revealed that most view their tenure as short term. ${ }^{22}$ However, the Centre management shares this view and considers the training and development of paralegals as an additional service to the field of family law. ${ }^{23}$

The Centre is committed to dispute resolution as an alternative mechanism to resolving legal conflicts wherever possible. To this end, a separate mediation division has been established, in order to ensure that the mediator is independent from the paralegal that sees the client. All clients are offered, and in fact encouraged to use, this as an alternative to the formal adversarial court process, especially if there is notice to 
defend. The mediation panel consists of a psychologist and two qualified attorneys. As the mediation is goal-oriented, the client is offered only two mediation sessions, unless the parties are very close to agreement. If more are needed, the client is either referred to the Family Mediation Associaton of the Cape (FAMAC) which offers a cheap rate, or if the client can pay, the Centre will offer more.

\section{FUNDING}

Whilst the prime function of the Centre is to provide an affordable professional service to the greater population, the Centre is also mindful of the fact that it must be self-sustaining. These conflicting aims of maximum access and the generating of sufficient funds to pay for the Centre's services formed the basis of the Centre's costing policy. All clients are charged a fee, which they are usually required to pay before any service is rendered. The amount charged is determined by a means test, and those people who do not pass the test are charged R50,00 irrespective of the nature of the legal problem. While this may appear a nominal charge, it is still substantial for the unemployed, given the income figures cited above. All other clients are charged a more marketrelated amount which ranges, depending on the nature of the service, from R350,00 to R670,00.

Even though these amounts are substantially lower than those charged by the formal profession, the rates do allow for a marginal over-recovery on the actual costs of service delivery. ${ }^{24}$ The excess will initially be used to supplement current salaries, as it is felt that this will enable the Centre to attract and retain top-quality staff members. ${ }^{25}$ Once the number of clients has increased to optimum level, the excess will be fed back into a sustainability fund that will be used to subsidise indigent clients. In the interim, the Centre has raised donor funding for this purpose. The Centre has also entered into an arrangement with the Legal Aid Board, in terms of which the Board has agreed to finance a set number of indigent clients, as it is recognised that the Centre's cost-of-service delivery is lower than the Board's own.

The initial set-up costs of the Centre were funded by the People's Bank through the Nedcor Foundation's Social Stabilisation Fund, ${ }^{26}$ whilst a launching base for indigent clients was provided by the Joffe Trust, a private family trust. The set-up funding is to cover a three-year period, and the first grant of R1 700 000,00 was used to establish the Cape Town Office. Two additional grants, totalling an estimated further

24 For example, at the time the Centre was established, an attorney charged on average between R3000,00 and R6000,00 for an undefended divorce whilst the Centre charged R630,00.

25 Interview (note 13 above).

26 Nedcor Foundation is the Social Responsibility arm of the Nedcor Banking Group and the People's Bank is one of its Black Empowerment Divisions. 
R3 400 000,00, will be used to finance additional centres in Durban and Johannesburg. ${ }^{27}$

\section{CASe Management ${ }^{28}$}

The cost of individual professional service is normally relatively high, as the cost of the professional's time required to establish and maintain such a relationship has to be recovered from the client. In contrast, the cost of an impersonal general service can be spread over a number of clients. In endeavouring to provide a cheaper service whilst simultaneously providing a personalised service, the Centre has devised an automated electronic system which is both standard and also allows for individual detail. Depending on the answers given to a series of simple questions that the computer prompts the paralegal to ask, the system predicts both the required procedures and apposite remedies, and the appropriate document is generated. If needs be, this document can then be tailored to specific needs by way of normal computer editing. Experts compiled the system, plotting the procedural steps in the respective areas of family law and drafting a bank of standard forms. Despite the predicted workflow, the Centre prides itself on offering a personalised service, and each client is afforded individual appointments with a designated paralegal. Interviews with a cross-section sample of clients confirmed that, without exception, clients felt that the service rendered was both friendly and helpful, and that they were sufficiently informed to finalise their matters themselves. As commented by one client when comparing this with her previous experience of the legal profession, "they tend to speak in their own language. Here I've been spoken to in a way that I can understand, which is very comforting and makes you feel better'. ${ }^{29}$

Irrespective of the nature of the problem, the process followed by the Centre consists of three broad phases. First, there is a screening process culminating in an appointment being made. There is a user education programme consisting initially of a video presentation, followed by an interview during which the legal principles are clarified and the individual's case details are extracted. Finally, there is a documentgenerating phase. The purpose of the initial screening, which is done telephonically, is twofold: to ascertain the nature of the problem and whether or not the Centre can assist. If the problem falls outside the scope of the areas of law covered by the Centre or requires specialised assistance, the client is either referred to an appropriate organisation or to a firm of attorneys. If this is not deemed necessary, an appointment is made with a specific paralegal. The costing scale is also ascertained 
during this discussion and the client is fully informed as to the cost implications.

The second phase involves the actual interview. The designated paralegal confirms the initial telephonic diagnosis and the client is then shown a video setting out the client's rights and obligations, and the appropriate procedural steps to be taken in order to obtain the particular relief sought. The interview is conducted in the client's mother-tongue, and the video presentations are available in the three main languages used in the Western Cape, namely English, Afrikaans and Xhosa. As and when the Project extends its offices to different areas, the videos and Centre's literature will be translated into the official languages most widely spoken in each area.

Once the client has viewed the video, which lasts for between ten and twenty minutes, ${ }^{30}$ a further interview is conducted by the same paralegal, during which the client's understanding of his or her rights and obligations and the legal requirements are consolidated and reaffirmed. While comprehensive, the aim of the video is to present a sufficiently clear scenario to enable even clients who are lacking in education to comprehend the content. An attempt to check whether the videos met this goal involved follow-up interviews with paralegals. Their experience bore out that the videos were a useful tool. However, when asked about the accessibility of the Centre's procedures to the less educated, the enthusiasm of responses varied. At one end of the scale, it was stated that

without fail, clients always invariably feel empowered by the whole process, and whether they succeed or fail, they feel knowledgeable and confident. The video plays a large role in this, especially when it comes to those who are illiterate.

Less confident answers included:

Sometimes if it is clear that the lights are not going on, the best tool to use is the video. Normally with a client who does not quite understand what is going on, the consultation will last for about ten minutes, and then the client will view the video. This puts the client on the same wavelength, and at least the consultant and the client are speaking apples and apples, rather than apples and pears. ${ }^{31}$

One indigent client, who had never received support for her twelve year old daughter from the child's father and had no prior knowledge regarding enforcement of maintenance matters, volunteered that the video 'was very, very clear. [It] is very good for people who need things explained over and over again'.32 Other interviews also highlighted the success of the user education programme, as all the clients interviewed expressed praise regarding the informative value of the video. As

30 Owing to the requirements of the language, the Xhosa video takes slightly longer than the others.

31 Interview with Centre paralegals (17 April 2003).

32 Interview with Centre maintenance client (31 May 2002). 
summarised by another client: 'The video was very informative and I did not have to ask one question after that'. ${ }^{33}$

The final phase involves the correct document being prepared, formalised and filed. ${ }^{34}$ The document is first checked by the paralegal and thereafter scrutinised by the Centre Management. Once the document is properly executed, the client is furnished with a copy, together with a mother tongue Resource Booklet that serves as an easily accessible resource document reinforcing the steps taken and those still required to finalise the matter. Interviews confirmed that at this stage, in line with the Centre's aims, all the clients felt sufficiently informed to finalise their matters on their own. All further support from the Centre is by answering telephonic enquiries from the client, which can be dealt with by any of the paralegals, as each paralegal has electronic access to a client's data base and can track the progress or status of that client's case. Clients appeared content with this arrangement, particularly as a common impression was that '... everyone knows what he or she is doing, ${ }^{35}$ and that the staff "have got time and listen, which is so important. They have time to take care'. ${ }^{36}$

\section{ViII A Preliminary Evaluation of the Family Court Centre Model}

For many people with family law problems, the Centre has signalled the first glimmer of hope of being able to obtain some legal relief. Many South Africans were previously unable to access any legal services because of their level of literacy and lack of finances. The Centre, through its integrated partnership and re-engineering of the service delivery process, has created opportunities that previously were preserved for a privileged few. As expressed by one client who for many years had tried to find her own way through the maintenance court:

This is the first place that has opened any doors for me. This thing has been going on since 1994 and I have gotten [sic] nowhere. ${ }^{37}$

Although the Centre offers its services to people from all walks of life, during its initial months of operation a large number of its clients have been indigent clients, raising questions as to the Centre's long-term ability to cross-subsidise its indigent clients. ${ }^{38}$ This will be particularly so when the Project extends its operation to rural areas. However, a greater awareness of the services offered should help bring in the many people

33 Interview with divorce client (note 29 above).

34 Provided the appropriate court falls within one of the ten Magisterial Districts within the Cape Metropolitan area, the Centre arranges for the document to be filed on behalf of the client. Matters involving claims of domestic violence are not filed by the Centre, as the courts insist that the applicant files the application him- or herself.

35 Interview (note 29 above).

36 Interview with Centre maintenance client (10 June 2002).

37 Interview with Centre maintenance client (6 June 2002).

38 Approximately 50.7 per cent of clients in the first four months were indigent 
who can afford to pay at least something for legal services, although not the expensive fees of the legal profession.

The government has long recognised the need to deal with family law matters in a holistic way. Family matters are currently dealt with by a variety of courts and with limited, if any, counselling and mediation support service available. Apart from the concomitant waste of time, duplication of work, manpower and expense, the fragmented system serves further to exacerbate the stress endured by those trying to navigate the system. The Family Court Centre appears, on initial evidence, to be a highly successful model for relieving the stress and difficulties of dealing with a complex system by means of personal assistance without costing very large amounts.

The model has the further advantage, given the way it has been set up, of apparently avoiding the two major problems of many public/private partnerships. The question of how far the Department should and can control the Centre's policy and operation appears to be answered by the cooperative way in which the newly instituted National Steering Committee and the Implementation Committee are working with the Centre's management. Most of the potential for conflict has also been removed, as the Centre is not housed within a private company, where the prime motivation is profit. However, the acid test will obviously come should one of the partners wish to act in a way unacceptable to the other.

As regards the second problem raised above, when the Project finally hands over its Centres to the Department, the computerised system and videos will contain the necessary information on how to run the system, as well as the details of cases seen, so that the withdrawal of expertise will not be disastrous. It would also possibly be helpful if the Centre could train Departmental staff on the system before the handover.

Meanwhile, the model appears to be highly successful. It is to be hoped that the demonstration by the Centre of the possibility of assisting indigent clients with legal information in a cheap but relatively personal manner will spur the government into investigating the use of the model for other branches of the law. Unless an environment is created where the justice system is easily accessible by all, the rights that the Constitution serves to protect will remain little more than symbols.

\section{SANDRA BURMAN* \\ Professor of Socio-Legal Studies, University of Cape Town NICHOLA GLASSER Senior Research Assistant, Centre for Socio-Legal Research University of Cape Town}

\footnotetext{
* The research was undertaken in 2002 and early 2003, and was sponsored by the National Research Foundation and the University of Cape Town Research Committee. The views expressed in this work and the conclusions drawn are those of the authors and should not be regarded as those of the sponsors.
} 